\title{
Development and Evaluation of Intranasal Mucoadhesiv Microspheres of Neostigmine Bromide
}

\author{
Basavaraj K. Nanjwade*, Kemy A. Parikh, Rucha V. Deshmukh, Veerendra K. Nanjwade, Kishori R. Gaikwad, Sachin A. Thakare and \\ F. V. Manvi
}

Department of Pharmaceutics, KLE University College of Pharmacy, Belgaum-590 010, Karnataka, India

\begin{abstract}
Purpose: Neostigmine bromide, a cholinesterase inhibitor is conventionally given by oral route for the treatment of myasthenia gravis. However, it is very poorly absorbed from gastro-intestinal tract. Intranasal administration is an ideal alternative to the parenteral route for systemic drug delivery. Formulating multiparticulate system with mucoadhesive polymers may provide a significant increase in the nasal residence time. The aim of the present approach was to overcome the drawbacks of the conventional dosage forms of Neostigmine Bromide by formulating intranasal microspheres with Carbopol 974P NF and HPMC K15 M along with film forming polymer ethyl cellulose.
\end{abstract}

Methods: The microspheres were prepared by emulsion solvent evaporation method. The prepared microspheres were characterized for encapsulation efficiency, drug loading, particle size, and surface morphology, degree of swelling, in-vitro mucoadhesion, drug release, in-vivo studies and stability studies.

Results: Formulations $\mathrm{IN}_{1}$ and $\mathrm{IN}_{5}$ displayed the best results for Carbopol and HPMC based microspheres respectively. Entrapment efficiency was $75.74 \pm 0.50 \%$ and $70.27 \pm 0.61 \%$; mucoadhesion was $98.5 \%$ and $85.3 \%$; and drug release up to $8 \mathrm{~h}$ was $87.86 \%$ and $84.5 \%$ for $\mathrm{IN}_{1}$ and $\mathrm{IN}_{5}$ respectively. In-vivo studies revealed that the formulations $I \mathrm{~N}_{1}$ and $I \mathrm{~N}_{5}$ showed good bioavailability compared to oral drug administration.

Conclusion: Both in-vitro and in-vivo studies conclude that Carbopol based microspheres are better than HPMC based microspheres for the delivery of Neostigmine Bromide.

Keywords: Mucoadhesive microspheres; Neostigmine Bromide; Cholinesterase inhibitor; Carbopol 974P NF; HPMC K15 M; Intranasal delivery

\section{Novelty of the Work}

Neostigmine Bromide is very known drug for the treatment of myasthenia gravis. However, its conventional oral route has disadvantage of poor bioavailability. Literature reports the evidence of good intranasal absorption of Neostigmine Bromide. Hence, an attempt has been made to develop intranasal mucoadhesive microspheres to increase the bioavailability and reduce the dosing frequency of the drug.

\section{Introduction}

The most desirable and convenient method of drug administration is the oral route because of their ease of administration. But lack of systemic absorption through the gastrointestinal tract led to research on alternate routes of drug delivery such as parenteral, intramuscular, subcutaneous, transdermal, etc [1]. Intranasal (IN) administration is a needle free and hence an ideal alternative to the parenteral route for systemic drug delivery. Nasal mucosa consists of a rich vasculature and a highly permeable structure for systemic absorption. Drug administration through the nasal cavity is easy and convenient. Avoidance of first pass metabolism is the main advantage of nasal route of drug delivery [2,3]. IN delivery is non-invasive, essentially painless, does not require sterile preparation, and is easily and readily administered by the patient or a physician, e.g., in an emergency setting. Given these positive attributes, it is logical to consider IN administration when developing new therapeutics, or when extending the life or improving the profile of an existing drug [4,5]. Subsequent to a drug's passage through the mucus, there are several mechanisms for absorption through the mucosa. These include transcellular or simple diffusion across the membrane (for lipophilic drugs), paracellular transport via movement between cell (for water soluble drugs) and transcytosis by vesicle carriers [6,7].

Microsphere carrier systems made from the biodegradable polymers have attracted considerable attention for several years in sustained drug delivery. However, the short residence time at the site of absorption could be overcome by coupling bioadhesion characteristics to microspheres and developing bioadhesive microspheres with the help of bioadhesive polymers $[8,9]$. Neostigmine Bromide - a cholinesterase inhibitor is widely used for the treatment of Myasthenia Gravis. It is presently marketed in conventional dosage form as a tablet in usual strength of 15-30 mg for peroral route [10]. Extent of absorption of drug through oral route is only $1-2 \%$ of $30 \mathrm{mg}$ of administered dose [11]. Hence there is need of novel nasal drug delivery system for the treatment of Myasthenia Gravis. To overcome inherent drawbacks associated with conventional dosage forms of Neostigmine Bromide, an attempt is being made in the present research work to develop an alternative drug delivery system in the form of Nasal mucoadhesive microspheres to increase the rate and extent of absorption and to reduce the dosing frequency of the formulation.

*Corresponding author: Dr. Basavaraj K. Nanjwade, Department of Pharmaceutics, KLE University College of Pharmacy,Belgaum-590010, Karnataka, India, Tel: 00919742431000; Fax: 00918312472387; E-mail: bknanjwade@yahoo. $\underline{\text { co.in }}$

Received December 07, 2010; Accepted April 05, 2011; Published April 08, 2011

Citation: Nanjwade BK, Parikh KA, Deshmukh RV, Nanjwade VK, Gaikwad KR, et al. (2011) Development and Evaluation of Intranasal Mucoadhesiv Microspheres of Neostigmine Bromide. Pharm Anal Acta 2:118. doi:10.4172/2153-2435.1000118

Copyright: (C) 2011 Nanjwade BK, et al. This is an open-access article distributed under the terms of the Creative Commons Attribution License, which permits unrestricted use, distribution, and reproduction in any medium, provided the original author and source are credited. 
Citation: Nanjwade BK, Parikh KA, Deshmukh RV, Nanjwade VK, Gaikwad KR, et al. (2011) Development and Evaluation of Intranasal Mucoadhesiv Microspheres of Neostigmine Bromide. Pharm Anal Acta 2:118. doi:10.4172/2153-2435.1000118

\section{Materials and Methods}

\section{Materials}

Neostigmine bromide was purchased from Sigma-Aldrich (Bangalore, India). Carbopol 974P NF was kindly gifted by Lubrizol Advanced Materials India Private Limited; while Ethyl Cellulose and Hydroxy propyl methyl cellulose was gifted by Colorcon Asia Pvt. Ltd. (Goa, India). All other chemicals used were of either laboratory or analytical grade.

\section{Methodology}

Method for preparation of microspheres: The NB loaded mucoadhesive microspheres were prepared by emulsion solvent evaporation method employing two different mucoadhesive polymers, viz. Carbopol 974P NF and HPMC K15 M. Ethyl cellulose was used as a rate controlling polymer.

Preparation of carbopol 974P NF microspheres: $0.9 \mathrm{~g}$ of Ethyl cellulose (EC) and Carbopol 974P NF (Cb) with two different $\mathrm{Cb} / \mathrm{EC}$ ratio $(1 / 5,1 / 3 \mathrm{w} / \mathrm{w})$ were dissolved in $20 \mathrm{ml}$ of ethanol using magnetic stirrer; weighed amount of NB was added to the EC-Cb solution under magnetic stirring. Then the suspension was quickly injected using a 5 $\mathrm{ml}$ syringe into $120 \mathrm{ml}$ of light liquid paraffin contained in a $250 \mathrm{ml}$ beaker, which contains $2.5 \%(\mathrm{v} / \mathrm{v})$ of Span 80 , while stirring using a mechanical stirrer. Stirring rate was kept at $8000 \mathrm{rpm}$ for $1 \mathrm{~min}$ to form a w/o emulsion. Stirring speed was then lowered and continued for $2 \mathrm{~h}$ at room temperature until ethanol evaporated completely and microspheres were formed. The formed microspheres were vacuum filtered through whatman filter paper. The residue was washed 2-3 times with $50 \mathrm{ml}$ portions of $\mathrm{n}$-hexane. The product was then dried for $24 \mathrm{~h}$ at room temperature [12].

Preparation of HPMC K15 M microspheres: The procedure employed for the preparation of HPMC K15 M microspheres was same as above. However, the internal solvent used was a mixture of ethanol and dichloromethane (1:1) instead of ethanol alone because of the insolubility of HPMC K15 M in ethanol.

All the formulations were prepared employing two different stirring speeds ( $700 \& 1200 \mathrm{rpm}$ ) for $2 \mathrm{~h}$ to see the effect of the same on particle size, entrapment efficiency and drug release characteristics. Table 1 shows the formulation variables of the prepared NB microspheres.

\section{Characterization of Microspheres}

\section{Production yield (\%)}

The production yield of microspheres of various batches were calculated using the weight of final product after drying with respect to the initial total weight of the drug and polymer used for preparation of microspheres and \% production yields were calculated as per the formula mentioned below [13].

$$
\% \mathrm{PY}=\mathrm{W}_{\mathrm{O}} / \mathrm{W}_{\mathrm{T}} \times 100
$$

$\mathrm{PY}=$ Production Yield; $\mathrm{W}_{\mathrm{O}}=$ Practical mass $\left(\right.$ microspheres); $\mathrm{W}_{\mathrm{T}}=$ Theoretical mass (Polymer + Drug).

\section{Encapsulation efficiency and drug loading}

To determine the amount of drug encapsulated in microspheres, a weighed amount $(50 \mathrm{mg})$ of microspheres was suspended into $50 \mathrm{ml}$ of dichloromethane and sonicated for $15 \mathrm{~min}$ in order to extract the entrapped drug completely. The solution was filtered through whatman filter paper. $1 \mathrm{ml}$ of this solution was withdrawn and diluted to $50 \mathrm{ml}$ with $\mathrm{pH} 6.4$ phosphate buffer solution. This solution was assayed for drug content by UV spectrophotometer at $261 \mathrm{~nm}$.

a) Encapsulation efficiency was calculated as: [14]

$$
\mathrm{EE}(\%)=\mathrm{ED} / \mathrm{AD} \times 100
$$

$\mathrm{EE}=$ Encapsulation efficiency; $\mathrm{ED}=$ Amount of encapsulated drug; $\mathrm{AD}=$ Amount of drug added.

b) Drug loading was calculated as: [15]

$$
\mathrm{DL}(\%)=\mathrm{W}_{\mathrm{D}} / \mathrm{W}_{\mathrm{T}} \times 100
$$

$\mathrm{DL}=$ Drug loading; $\mathrm{W}_{\mathrm{D}}=$ Weight of drug loaded in microspheres; $\mathrm{W}_{\mathrm{T}}=$ Total weight of microspheres.

\section{Particle size analysis}

Particle size of different batches of microspheres was determined by optical microscopy. The projected diameter of microspheres from each batch was determined using ocular micrometer and stage micrometer equipped with optical microscope. Analysis was carried out by observing the slide containing microspheres under the microscope. The average particle size of the microspheres was expressed as diameter.

\section{Surface morphology}

Shape and surface morphology of microspheres was studied using scanning electron microscopy (SEM) [16,17]. The microspheres were mounted on metal stubs and the stub was then coated with conductive gold with sputter coater attached to the instrument. The photographs were taken using a Jeol scanning electron microscope (JEOL-JSMAS430, Japan).

\section{Degree of swelling [18]}

The swell ability of microspheres in physiological media was

\begin{tabular}{|c|c|c|c|c|c|c|}
\hline \multirow{2}{*}{$\begin{array}{l}\text { Mucoadhesive } \\
\text { Polymer }\end{array}$} & \multirow{2}{*}{ Formulation Code } & \multicolumn{2}{|l|}{ Amount of Polymer $(0.9 \mathrm{~g})$} & \multirow{2}{*}{ Polymer Ratio (w/w) } & \multirow{2}{*}{ Stirring Speed } & \multirow{2}{*}{ Amount of Drug (mg) } \\
\hline & & Mucoadhesive Polymer (mg) & Film Forming Polymer (mg) & & & \\
\hline \multirow{4}{*}{$\begin{array}{l}\text { Carbopol 974P } \\
\text { NF }\end{array}$} & IN1 & 0.225 & 0.675 & $1 / 3$ & 700 & 100 \\
\hline & IN2 & 0.225 & 0.675 & $1 / 3$ & 1200 & 100 \\
\hline & IN3 & 0.150 & 0.750 & $1 / 5$ & 700 & 100 \\
\hline & IN4 & 0.150 & 0.750 & $1 / 5$ & 1200 & 100 \\
\hline \multirow{4}{*}{$\begin{array}{l}\text { HPMC } \\
\text { K15 M }\end{array}$} & IN5 & 0.225 & 0.675 & $1 / 3$ & 700 & 100 \\
\hline & IN6 & 0.225 & 0.675 & $1 / 3$ & 1200 & 100 \\
\hline & IN7 & 0.150 & 0.750 & $1 / 5$ & 700 & 100 \\
\hline & IN8 & 0.150 & 0.750 & $1 / 5$ & 1200 & 100 \\
\hline
\end{tabular}
determined by swelling them in the PBS $\mathrm{pH}$ 6.4. Accurately weighed amount of microspheres was immersed in little excess of $\mathrm{PBS} \mathrm{pH} 6.4$ for

Table 1: Formulation table of NB microspheres. 


\begin{tabular}{|l|l|l|l|l|l|l|}
\hline Formulation Code & Production Yield (\%) & Entrapment Efficiency* (\%) & Drug Loading* (\%) & Mean Particle Size* & Degree of Swelling* $^{*}$ & Muco-adhesion (\%) $^{*}$ \\
\hline IN1 & 79.2 & $75.74 \pm 0.50$ & $7.57 \pm 0.05$ & $362.45 \pm 4.12$ & $1.63 \pm 0.012$ \\
\hline IN2 & 75.3 & $72.94 \pm 0.61$ & $7.29 \pm 0.06$ & $334.57 \pm 6.24$ & $1.61 \pm 0.011$ \\
\hline IN3 & 77.1 & $68.34 \pm 0.90$ & $6.84 \pm 0.09$ & $355.12 \pm 5.69$ & $1.57 \pm 0.010$ \\
\hline IN4 & 74.4 & $67.70 \pm 0.56$ & $6.77 \pm 0.06$ & $326.48 \pm 4.38$ & $1.56 \pm 0.010$ \\
\hline IN5 & 86.4 & $70.27 \pm 0.61$ & $7.03 \pm 0.06$ & $310.58 \pm 7.17$ & $1.16 \pm 0.009$ \\
\hline IN6 & 82.9 & $68.94 \pm 0.64$ & $6.89 \pm 0.06$ & $274.25 \pm 4.43$ & $1.10 \pm 0.008$ \\
\hline IN7 & 85.3 & $64.47 \pm 0.70$ & $6.45 \pm 0.07$ & $301.31 \pm 5.83$ & $1.03 \pm 0.008$ \\
\hline IN8 & 82.1 & $62.00 \pm 0.72$ & $6.20 \pm 0.06$ & $262.59 \pm 5.18$ & 84.3 \\
\hline
\end{tabular}

*Mean \pm S.D. $(n=3)$

Table 2: Characterization of microspheres

\begin{tabular}{|c|c|c|c|c|c|}
\hline \multirow{2}{*}{ Formulation } & \multicolumn{5}{|c|}{ Pharmacokinetic Parameters } \\
\hline & Tmax (h) & Cmax (ng/ml) & AUC (ng.h/ml) & $\operatorname{Kel}\left(\mathbf{h}^{-1}\right)$ & t1/2 (h) \\
\hline Oral & 1.5 & 60.07 & 94.17 & 0.582 & 1.19 \\
\hline $\mathrm{IN}_{1}$ & 3 & 95.51 & $446.25^{\star}$ & 0.164 & 4.22 \\
\hline $\mathrm{IN}_{5}$ & 3 & 90.32 & $406.85^{\star}$ & 0.196 & 3.53 \\
\hline
\end{tabular}

${ }^{*} \mathrm{p}<0.05$

Table 3: Pharmacokinetic parameters of oral tablet and nasal microspheres of Neostigmine Bromide.

$24 \mathrm{~h}$ and washed. The degree of swelling was calculated using following formula:

$$
a=\left(\mathrm{W}_{\mathrm{s}}-\mathrm{W}_{\mathrm{o}}\right) / \mathrm{W}_{\mathrm{o}}
$$

$a$ is the degree of swelling; $W_{o}$ is the weight of microspheres before swelling; $\mathrm{W}_{\mathrm{s}}$ is the weight of microspheres after swelling.

\section{In-vitro mucoadhesion studies [18]}

Mucoadhesion of microspheres was assessed using the method reported by Jain et al. with little modification. Briefly, a small portion of the goat nasal mucosa was mounted on a glass slide and accurately weighed microspheres were sprinkled on the mucosa. This glass slide was kept in desiccator for $15 \mathrm{~min}$ to allow the polymer to interact with the membrane and finally placed in the cell that was attached to the outer assembly at an angle of $45^{\circ}$. Phosphate buffer solution $\mathrm{pH}$ 6.4, previously warmed to $37 \pm 5^{\circ} \mathrm{C}$ was circulated all over the microspheres and membrane at the rate of $1 \mathrm{ml} / \mathrm{min}$. Washings were collected at different time intervals and microspheres were collected by centrifugation followed by drying at $50^{\circ} \mathrm{C}$. The weight of washed out microspheres was determined and percent mucoadhesion was calculated by following formula:

$$
\% \text { Mucoadhesion }=\left(\mathrm{W}_{\mathrm{a}}-\mathrm{W}_{\mathrm{l}}\right) \times 100 / \mathrm{W}_{\mathrm{a}}
$$

Where, $\mathrm{W}_{\mathrm{a}}$ = weight of microspheres applied; $\mathrm{W}_{1}=$ weight of microspheres leached out.

\section{In vitro drug release studies [19]}

Drug release from the microspheres was carried out using a beaker method incorporating phosphate buffer solution $\mathrm{pH} 6.4$ as the release medium. A weighed amount of microspheres, equivalent to $20 \mathrm{mg}$ of Neostigmine Bromide, were suspended in $50 \mathrm{ml}$ of the dissolution medium in $250 \mathrm{ml}$ beaker and stirred on a magnetic stirrer at $50 \mathrm{rpm}$ at $37^{\circ} \mathrm{C} .2 \mathrm{ml}$ sample was withdrawn at appropriate time intervals and centrifuged at $5000 \mathrm{rpm}$. Supernatants were diluted suitably and absorbance of the resulting solution was measured at $261 \mathrm{~nm}$ in a double-beam UV spectrophotometer using the dissolution medium as blank. The residue was redispersed in $2 \mathrm{ml}$ of the fresh dissolution medium and replaced back into the vials.

\section{In-vivo bioavailability studies}

Out of eight formulations, two were selected (one each of Carbopol and HPMC based microspheres) for in vivo bioavailability studies on the basis of data of the in-vitro results. In-vivo bioavailability studies were conducted on healthy male rabbits weighing around $2.5 \mathrm{~kg}$. This study received the approval of the institutional animal ethics committee of J. N. Medical College, KLE University, Belgaum. Six rabbits were divided into three groups and fasted for $24 \mathrm{~h}$. One batch was fed with the oral tablet preparation (equivalent to $2.6 \mathrm{mg}$ of drug); while other two batches were given the formulations IN1 and IN5 (equivalent to 2.4 $\mathrm{mg}$ of drug). Water was given ad libitum during fasting and throughout the experiment. Blood samples of $2 \mathrm{ml}$ were collected from the marginal ear vein of the rabbits into heparinized centrifuge tubes at $0.5,1,2,3$, 4, 5, 6, 7 and $8 \mathrm{~h}$ after the drug administration. The blood samples were centrifuged at $3000 \times \mathrm{g}$ for $15 \mathrm{~min}$ to obtain the plasma and stored at $-20^{\circ} \mathrm{C}$ until analysis. The extraction of drug from plasma was carried out as reported previously and then injected into the HPLC system [20]. The mobile phase used was acetonitrile: $80 \mathrm{mM}$ sodium sulphate solution (60:40) at a flow rate of $1.5 \mathrm{ml} / \mathrm{min}$.

\section{Pharmacokinetic analysis}

Pharmacokinetic parameters were derived from the plasma concentration vs. time plot. The area under the curve (AUC), the peak plasma concentration $\left(\mathrm{C}_{\max }\right)$ and the time to attain peak concentration $\left(\mathrm{T}_{\max }\right)$ were obtained from these plots. The elimination rate constant $\left(\mathrm{K}_{\mathrm{el}}\right)$ was determined from the semi-logarithmic plot of plasma concentration vs. time. Elimination half-life $\left(t_{1 / 2}\right)$ was calculated using the formula; $\mathrm{t}_{1 / 2}=0.693 / \mathrm{K}_{\mathrm{el}}$. AUC was statistically analyzed applying one-way ANOVA at 0.05 levels in the GraphPad Prism version 5.01 software.

\section{Results}

The microspheres obtained for all the formulations were discrete and uniform. The production yield, entrapment efficiency, drug loading, particle size, degree of swelling and percent mucoadhesion of all the batches of microspheres is depicted in Table 2.

The production yields of microspheres were found to be between 74 to $87 \%$. The values for entrapment efficiency and drug loading were in the range of 67 to $76 \%$ and 6.5 to $7.5 \%$ respectively for Carbopol based microspheres; while for HPMC based microspheres, they were in the range of 62 to $70 \%$ and 6.2 to $7 \%$ respectively. Mean particle size of Carbopol based microspheres was higher than that of HPMC based 
microspheres. Also, particle size was reduced at higher stirring rate. The degree of swelling and percent mucoadhesion was higher for Carbopol while comparing with HPMC based microspheres. Scanning electron micrographs of formulations $\mathrm{IN}_{1}$ and $\mathrm{IN}_{5}$ are as shown in Figure 1 and 2 which indicated that the microspheres were discrete, uniform and spherical with a smooth surface.

The cumulative percent drug release was found to be $87.86 \%$, $103.54 \%, 81.61 \%, 101.15 \%, 84.5 \%, 101.91 \%, 78.21 \%$ and $100.11 \%$, respectively for the formulations IN1 to IN8. The comparative release studies of Carbopol and HPMC based microspheres are graphically shown in Figures 3 and 4 respectively. The release pattern of Neostigmine Bromide from all the formulations showed a biphasic drug release pattern, characterized by an initial burst effect followed by slow release. Formulations $\mathrm{IN}_{2}, \mathrm{IN}_{4}, \mathrm{IN}_{6}$ and $\mathrm{IN}_{8}$ showed almost complete drug release within $7 \mathrm{~h}$ while rest other formulations showed controlled release of drug up to $8 \mathrm{~h}$.

From the results obtained from in vivo pharmacokinetic study, plasma concentration was plotted against time and is shown in Figure 5.

The mean pharmacokinetic parameters of the oral and nasal formulations were estimated and are given in Table 3.

\section{Discussion}

Initially, the optimization of process and formulation variables was carried out which showed that emulsion solvent evaporation method with w/o type of emulsion system is feasible for preparation of microspheres for water soluble compounds. Neostigmine Bromide (NB) is highly water soluble, as well as is soluble in organic solvents (ethanol, methanol) while ethyl cellulose is insoluble in water. So, in the present investigation, organic solvent was used as polar phase (representing aqueous phase) to form w/o type of system [21]. Initially, methanol was employed as polar internal organic solvent phase for preparation of microspheres but the microspheres obtained were not spherical in shape. To avoid this problem, ethanol was tried instead of methanol. Ethanol is a good solvent for most water-soluble drugs and waterinsoluble polymers, and is non-toxic. It remained dispersed as droplets in the oily phase leading to formation of stable emulsion. Ethanol may have worked because it has a high boiling point in relation to methanol which was able to prevent immediate polymer precipitation. However, the mucoadhesive polymer HPMC K15 M is not soluble in ethanol. Therefore, combination of ethanol and dichloromethane was used for preparing HPMC K15 M based microspheres. It was observed that the microspheres so obtained were spherical with a smooth surface. For the washing of the prepared microspheres, initially petroleum ether was utilized. However, the microspheres obtained were not discrete in nature and formed the lumps. Finally, n-hexane was tried in which liquid paraffin is soluble but polymers are not. The microspheres obtained so were discrete in nature.

It was found that production yield of microspheres prepared by HPMC K15 M was greater than Carbopol 974P NF. The probable reason behind this may be the high viscosity of the Carbopol solution which decreased its syringeability resulting in blocking of needle and wastage of the drug- polymer solution which ultimately decreased the production yields of microspheres [22]. Another reason for that may be the agglomeration and sticking of polymer to blades of stirrer and to the wall of the beaker during microsphere formation. As the concentration of mucoadhesive polymer increased, entrapment efficiency increased both at higher and lower stirring rate. However, Carbopol had higher effect on entrapment efficiency than HPMC. This may be attributed to higher molecular weight of Carbopol than HPMC. Increase in the molecular weight of the mucoadhesive polymer increases the encapsulation efficiency of the microspheres due to formation of more intact matrix network [22]. Particle size mainly depends on the stirring rate; hence, as the stirring rate increased, the particle size decreased irrespective of the concentration of mucoadhesive polymer. While concentration of mucoadhesive polymer had opposite effect in particle size. From the surface morphology results, microspheres obtained were discrete, uniform and spherical with a smooth surface. This can be attributed to the slow solvent evaporation and slow precipitation of polymers during formation of w/o type of emulsion.

From the Table 2, it is known that the degree of swelling increases marginally as the concentration of mucoadhesive polymer increases. Marginal decrease in swelling at lower level of mucoadhesive polymer may be due to the higher level of film forming polymer (ethyl cellulose)

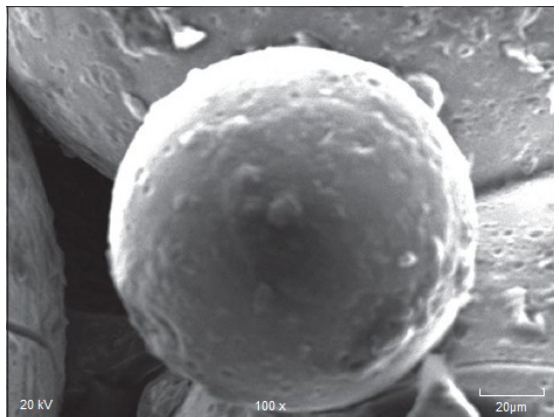

Figure 1: Scanning Electron Microphotograph of Carbopol Based Microspheres of Neostigmine Bromide (Formulation $\mathrm{IN}_{1}$ ).

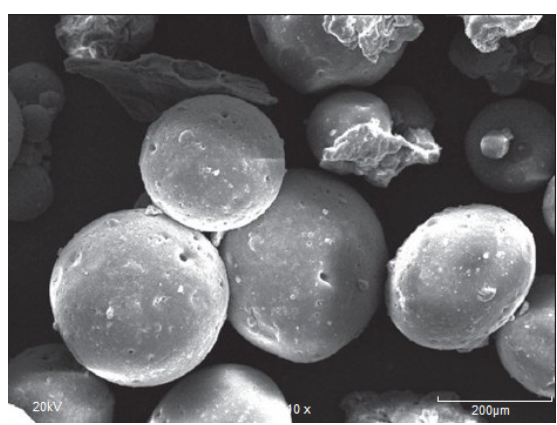

Figure 2: Scanning Electron Microphotograph of HPMC Based Microspheres of Neostigmine Bromide (Formulation $\mathrm{IN}_{5}$ ).

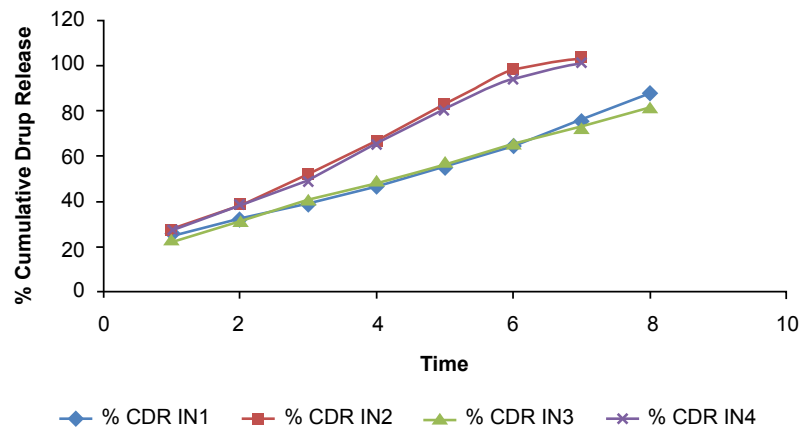

Figure 3: In vitro Release Profile of Carbopol Based Microspheres Formulations. 


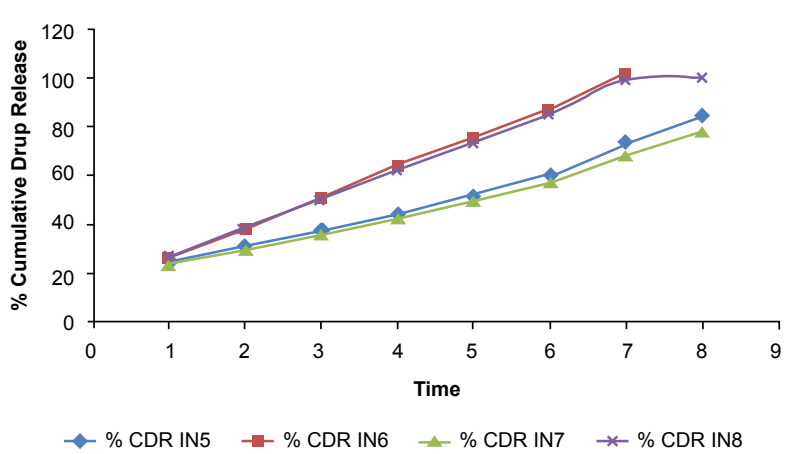

Figure 4: In vitro Release Profile of HPMC Based Microspheres Formulations.

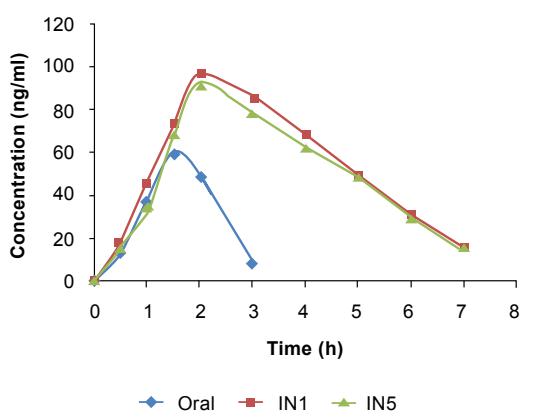

Figure 5: Plot of plasma concentration of Neostigmine Bromide vs. time.

in those formulations which allows lesser penetration of water inside the polymer matrix. Higher degree of swelling of Carbopol microspheres than HPMC microspheres may be due to higher molecular weight of Carbopol than HPMC. \% mucoadhesion increased with the increase in concentration of mucoadhesive polymer. The higher mucoadhesion of Carbopol microspheres may also be attributed to the higher molecular weight of Carbopol than HPMC. Furthermore, HPMC being non-ionic possesses low hydrogen bonding capability with mucus membrane.

From the results obtained of in vitro release study, it was clear that as the concentration of mucoadhesive polymer increased, the drug release also increased proportionally. Drug release increased steeply as the stirring rate was increased from lower to higher level. This presumably is due to the smaller particle size of microspheres at higher stirring rate which leads to much larger surface area available for release and a shorter pathlength for drug to diffuse through microspheres. The greater drug release from Carbopol microspheres than HPMC microspheres may be due to the higher swelling degree of Carbopol than HPMC which forms hydrophilic passages inside the microspheres who help drug diffuse out. The increase of hydrophilic pores formed by Carbopol facilitated the water penetrating into microspheres, accelerated the erosion of the swelling matrix and resulted in a combination of the diffusion and erosion mechanisms of drug release from microspheres. The initial burst effect of drug released from microspheres was mainly seen due to the portion of the drug located on the surface of the microspheres followed by the diffusion of the drug through the polymer matrix. From the in vitro release graph, formulations $\mathrm{IN}_{1}$ and $\mathrm{IN}_{5}$ were selected as the best formulations for Carbopol and HPMC microspheres respectively as they showed controlled release of drug up to $8 \mathrm{~h}$. While formulations $\mathrm{IN}_{2}, \mathrm{IN}_{4}, \mathrm{IN}_{6}$ and IN8 showed the complete drug release within $7 \mathrm{~h}$. Formulations $\mathrm{IN}_{3}$ and $\mathrm{IN}_{7}$ also showed controlled release of drug but drug release was lower than $\mathrm{IN}_{1}$ and $\mathrm{IN}_{5}$ up to $8 \mathrm{~h}$. Owing to the residence time of the formulation in the nasal cavity from the in-vitro mucoadhesion test and all other in vitro study parameters, formulation $\mathrm{IN}_{1}$ and $\mathrm{IN}_{5}$ were given the priority over $\mathrm{IN}_{3}$ and $\mathrm{IN}_{7}$ for Carbopol and HPMC microspheres respectively.

For in vivo evaluation of nasal microspheres of Neostigmine Bromide, rabbit was chosen as a model for study because the blood volume of the rabbit is sufficiently large (approximately $300 \mathrm{ml}$ ) to permit frequent blood sampling and allow a full characterization of the absorption and determination of the pharmacokinetic profile of the drug. The Cmax after oral dosing was found to be $60.07 \mathrm{ng} / \mathrm{ml}$ and the corresponding Tmax was $1.5 \mathrm{~h}$. It was observed that the concentration of drug in the plasma decreased very fast after the Cmax was attained for oral group. The concentration obtained at $3 \mathrm{~h}$ was $8.11 \mathrm{ng} / \mathrm{ml}$. The concentration range in the subsequent hours was in the traces and was out of the limit of detection. While for intranasal formulations, The Cmax attained was 95.51 and $90.32 \mathrm{ng} / \mathrm{ml}$ for $\mathrm{IN}_{1}$ and $\mathrm{IN}_{5}$ respectively. The corresponding Tmax was $3 \mathrm{~h}$ for both the formulations. After attaining Cmax, the formulation showed controlled release of drug up to $7 \mathrm{~h}$. The relative bioavailability of the $\mathrm{IN}_{1}$ formulation compared to oral was found to be 5.13 while for $\mathrm{IN}_{5}$ it was formulation was 4.68 . Thus, bioavailability of Neostigmine Bromide was found to have significantly increased by formulating the drug for nasal drug delivery as compared to the oral route.

\section{Conclusion}

The present study has been satisfactorily attempted to formulate a mucoadhesive microparticulate system of an anticholiesterase drug like Neostigmine Bromide for intranasal administration with a view of enhancing bioavailability of the drug. \% entrapment efficiency was higher for Carbopol based microspheres than HPMC based microspheres. While practical yield obtained was higher for HPMC based microspheres. The particle size analysis revealed that all formulations gave particles in the range of $250-400 \mu \mathrm{m}$ which is suitable for intranasal administration of formulation. SEM analysis of the microspheres revealed that all the formulations were smooth and spherical with ideal surface morphology. Increase in the mucoadhesive polymer led to increase in mucoadhesion and degree of swelling. However, Carbopol showed higher mucoadhesion and swelling degree than HPMC. As the concentration of mucoadhesive polymer increased, the drug release also increased proportionally. Stirring rate had more influence on drug release than concentration of mucoadhesive polymer. Assessment of AUC showed that the relative bioavailability of was 5.13 and 4.68 for $\mathrm{IN}_{1}$ and $\mathrm{IN}_{5}$ respectively. From all the parameters studied, it can be concluded that Carbopol 974P NF is better mucoadhesive polymer than HPMC K15 M for the formulation of mucoadhesive microspheres of Neostigmine Bromide for intranasal administration. Thus, the formulated microspheres seem to be a potential candidate as intranasal controlled drug delivery system for symptomatic therapy of myasthenia gravis.

\section{Acknowledgements}

We are very grateful to the Vice-Chancellor and Registrar of K.L.E. University and also would like to thank Managing Director and CEO of Dr. Prabhakar Kore Hospital and Research Centre, Belgaum for providing constant support and enthusiasm to carry out this work.

\section{References}

1. Behl CR, Pimplaskar HK, Sileno AP, deMeireles J, Romeo VD (1998) Effects of physicochemical properties and other factors on systemic nasal drug delivery Adv Drug Deli Rev 29: 89-116. 
Citation: Nanjwade BK, Parikh KA, Deshmukh RV, Nanjwade VK, Gaikwad KR, et al. (2011) Development and Evaluation of Intranasal Mucoadhesiv Microspheres of Neostigmine Bromide. Pharm Anal Acta 2:118. doi:10.4172/2153-2435.1000118

2. Chein YW (1992) Novel drug delivery systems. $2^{\text {nd }}$ ed., Marcel Dekker, Inc., New York, NY, 229.

3. Arora P, Sharma S, Garg S (2002) Permeability issues in nasal drug delivery. Drug Discov Today 7: 967-975.

4. Costantino HR, Illum L, Brandt G, Johnson PH, Quay SC (2007) Intranasal delivery: Physicochemical and therapeutic aspects. Int J Pharm 337: 1-24.

5. Turker S, Onur E, Ozer Y (2004) Nasal route and drug delivery systems. Pharm World Sci 26: 137-142.

6. Jadhav KR, Gambhire MN, Shaikh IM, Kadam VJ, Pisal SS (2007) Nasal Drug Delivery System-Factors Affecting and Applications. Current Drug Therapy 2: 27-38.

7. Aurora J (2002) Development of Nasal Delivery Systems: A Review. Drug Deliv Technol 7: 1-8.

8. Benita S (1996) Microencapsulation methods and industrial applications. Inc, New York, NY, 35-71.

9. Lee WT, Robinson JR (2003) Controlled release drug delivery systems, in Gennaro AR, Remington: The science and practice of pharmacy. $21^{\text {th }}$ ed., Lippincott Williams and Wilkins, Philadelphia, 1: 953-962.

10. Tripathi KD (2003) Essentials of medical pharmacology. $5^{\text {th }}$ ed. Jaypee Brothers Medical Publishers $(P)$ Ltd, New Delhi.

11. http://www.rxlist.com/prostigmin-drug.htm,(Accessed on 06th March. 2010)

12. Tao Y, Lu Y, Sun Y, Gu B, Lu W, et al. (2009) Development of mucoadhesive microspheres of acyclovir with enhanced bioavailability. Int J Pharm 378: 30-36.

13. Cevher E, Orhan Z, Mulazimoglu L, Sensoy D, Alper M, et al. (2006) Characterization of biodegradable chitosan microspheres containing vancomycin and treatment of experimental osteomyelitis caused by methicillinresistant staphylococcus aureus with prepared microspheres. Int J Pharm 317: $127-135$
14. Mathew ST, Gayathri Devi S, Sandhya KV (2007) Formulation and evaluation of ketorolac tromethamine-loaded albumin microspheres for potentia intramuscular administration. AAPS Pharm Sci Tech 8: 14.

15. Trivedi P, Verma A, Garud N (2008) Preparation and characterization of aceclofenac microspheres. Asian J Pharm 2: 110-115.

16. Selek H, Sahin S, Kas HS, Hinkal AA, Ponchel G, et al. (2007) Formulation and characterization of formaldehyde cross-linked degradable starch microspheres containing terbutalin sulphate. Drug Dev Ind Pharm 33: 147-154.

17. Srivastava AK, Ridhurkar DN, Wadhwa S (2005) Floating microspheres of cimetidine: formulation, characterization and in vitro evaluation. Acta Pharm 55: $277-285$

18. Jain SK, Jain NK, Gupta Y, Jain A, Jain D, et al. (2007) Mucoadhesive chitosan microspheres for non-invasive and improved nasal delivery of insulin. Indian $\mathrm{J}$ Pharm Sci 69: 498-504.

19. Thakkar H, Sharma RK, Mishra AK, Chuttani K, Murthy RR (2005) Albumin microspheres as carriers for the antiarthritic drug celecoxib. AAPS Pharm Sci Tech 6: 65-73.

20. Varin F, Couture J, Gao H (1999) Determination of neostigmine in human plasma and cerebrospinal fluid by high-performance liquid chromatography with ultraviolet detection. J Chromatogr B Biomed Sci Appl 723: 319-323.

21. El-Bagory IM, Hosny EA, Al-Suwayeh SA, Mahrous GM, Al-Jenoobi FI (2007) Effects of sphere size, polymer to drug ratio and plasticizer concentration on the release of theophylline from ethylcellulose microspheres. Saudi Pharmaceutical Journal 15: 213-7.

22. Belgamwar V, Shah V, Surana SJ (2009) Formulation and Evaluation of Ora Mucoadhesive Multiparticulate System Containing Metoprolol Tartarate: An In Vitro - ex Vivo Characterization. Curr Drug Deliv 6: 113-21. 